\title{
The Effect of Oxygen Enrichment on Soot Formation and Thermal Radiation in Turbulent, Non-Premixed Methane Flames
}

\author{
Christopher R. Shaddix and Timothy C. Williams \\ Combustion Research Facility \\ Sandia National Laboratories \\ Livermore, California 94550
}

\begin{abstract}
Non-premixed oxy-fuel combustion of natural gas is used in industrial applications where high-intensity heat is required, such as glass manufacturing and metal forging and shaping. In these applications, the high flame temperatures achieved by oxy-fuel combustion increase radiative heat transfer to the surfaces of interest and soot formation within the flame is desired for further augmentation of radiation. However, the high cost of cryogenic air separation has limited the penetration of oxy-fuel combustion technologies. New approaches to air separation are being developed that may reduce oxygen production costs, but only for intermediate levels of oxygen enrichment of air. To determine the influence of oxygen enrichment on soot formation and radiation, we developed a non-premixed coannular burner in which oxygen concentrations and oxidizer flow rates can be independently varied, to distinguish the effects of turbulent mixing intensity from oxygen enrichment on soot formation and flame radiation. Local radiation intensities, soot concentrations, and soot temperatures have been measured using a thinfilm thermopile, planar laser-induced incandescence (LII), and two-color imaging pyrometry, respectively. The measurements show that soot formation increases as the oxygen concentration decreases from $100 \%$ to $50 \%$, helping to moderate a decrease in overall flame radiation. An increase in turbulence intensity has a marked effect on flame height, soot formation and thermal radiation, leading to decreases in all of these. The soot temperature decreases with a decrease in the oxygen concentration and increases with an increase in turbulent mixing intensity. Overall, the results suggest that properly designed oxygen-enriched burners that enhance soot formation for intermediate levels of oxygen purity
\end{abstract}


may be able to achieve thermal radiation intensities as high as $85 \%$ of traditional oxy-fuel burners utilizing high-purity oxygen.

Keywords: oxy-fuel; flame; methane; soot; radiation

\section{Introduction}

Oxy-fuel combustion is a well-known approach for improving the thermal efficiency of hightemperature industrial furnaces [1-3]. The efficiency improvement results from the greater radiant emission from oxy-fuel flames, a consequence of the higher flame temperatures and greater emissivity of the product gases. The peak flame temperature during pure oxy-fuel combustion of natural gas is nearly $3000 \mathrm{~K}$, compared to a peak temperature during air-firing of about $2200 \mathrm{~K}$. Absent the dilution from $\mathrm{N}_{2}$ associated with air-based combustion, the concentrations of $\mathrm{CO}_{2}$ and steam (both of which are radiantly active) in the products of oxy-fuel flames are 3.5 times greater than in air-fuel flames. As a result, up to $98 \%$ of the heat transfer from oxy-fuel flames to the 'batch' (the solid particle components that will make up the glass) in glass-melting furnaces has been shown to be through radiation [1]. Overall, glass melting furnaces and steel heating furnaces have shown 20-60\% improvement in furnace efficiency when retrofitting from air-fired to oxy-fired operation [3-5]. However, producing oxygen through air separation consumes a large amount of energy, such that the overall system efficiency when switching to oxy-fuel firing may or may not improve, depending on the original furnace efficiency and the energy efficiency of oxygen production.

The penetration of oxy-fuel technology into industrial markets is currently constrained by the high cost of commercial air separation technologies. Cryogenic air separation is the most widely used technology for generating oxygen at a large scale [6,7]. This approach generates oxygen with a purity of 90-99.5\% and can scale to large single-unit production sizes. Unfortunately, it is a complex and 
expensive technology. Pressure swing adsorption (PSA) is a competing technology for relatively smallscale applications that do not require oxygen purity greater than $94 \%$. Current PSA systems rely on preferential adsorption of $\mathrm{N}_{2}$ onto zeolytes and consist of a multi-step batch production process [6-8].

New advances in materials science offer the prospect of lower-cost production of oxygen-enriched air via membranes (e.g. ion-transport membranes $[9,10]$ ) or through adsorption approaches with novel materials. Recently, a new class of materials known as metal-organic frameworks (MOFs) has been developed, featuring large surface areas and open metal coordination sites for gas adsorption [11]. Some preliminary studies of MOFs for air separation have been conducted, and recent work at Sandia National Laboratories has identified promising MOFs structures and compositions for improved air separation $[12,13]$. In the future, the use of MOFs or other advanced materials may allow cost-effective oxygen production at near-ambient temperatures, but with an imperfect purity. If carbon capture from the exhaust is desired, having a high-purity oxygen stream is of paramount importance.

Within this context, the question arises as to the level of oxygen enrichment necessary to achieve the desired heat transfer in industrial oxy-fuel applications. Specifically, one would like to know how much enhancement in radiative heating is possible with different levels of oxygen enrichment, and how oxygen-enriched burners can be designed to maximize radiant emission. The presence of soot within a flame is known to enhance radiant heat transfer, potentially to a significant extent [14-16]. The relationship between turbulent mixing, soot formation, and flame radiation in oxygen-enriched methane flames has not been previously explored in depth. Baukal and Gebhart [17] varied $\mathrm{O}_{2}$ levels from $28 \%$ to $100 \%$ in a rapid mixing burner firing natural gas from laminar to turbulent flow and across a range of overall stoichiometries. They measured "non-luminous" thermal radiation (i.e. without soot contributions) and found it to increase rapidly with oxygen purity, with only a small tapering of the rate of increase as the oxidizer composition approached the pure oxygen limit. Wang et al. [18] studied mean soot formation and thermal radiation from a series of natural gas and propane flames formed by injecting 
turbulent fuel jets into low-velocity laminar oxidizer streams consisting of $21 \%$ to $100 \% \mathrm{O}_{2}$. They found a peak soot volume fraction for $70 \% \mathrm{O}_{2}$ when using a modestly turbulent fuel jet $(\mathrm{Re}=5000)$ and a peak soot volume fraction for $35 \% \mathrm{O}_{2}$ when using a more strongly turbulent fuel jet $(\mathrm{Re}=15000)$.

Here, we expand upon these previous studies by utilizing more realistic turbulent flows of both methane and oxidizer and by keeping the stoichiometry of supplied burner gases near one, as is practically relevant. We report detailed, spatially resolved measurements of both radiation and soot concentrations, as well as mean soot temperature in these flames.

\section{Experimental Description}

\subsection{Turbulent co-annular burner}

For this investigation a co-annular burner geometry was selected in which the fuel is emitted from a 4.76 mm outer diameter (OD) smooth, seamless stainless steel tube that is surrounded by a $12.70 \mathrm{~mm}$ OD smooth, seamless stainless steel tube in which the oxidizer flows (see Fig. 1). The internal diameter (ID) of the fuel tube is $3.34 \mathrm{~mm}$ and that of the oxidizer tube is $10.21 \mathrm{~mm}$. Both tubes have straight-cut ends to facilitate flame holding, with the fuel tube penetrating $1 \mathrm{~mm}$ beyond the oxidizer tube. The fuel and oxidizer tubes have lengths of $80 \mathrm{~cm}$ and $55 \mathrm{~cm}$, respectively. Wire spacers recessed $140 \mathrm{~mm}$ from the burner tip are used to centralize the fuel tube. The theoretical length needed for fully developed turbulent pipe flow under our operating conditions ranges from 94 to $106 \mathrm{~mm}$. Similarly, the fuel tube is four times longer than required to form fully developed pipe flow. Outside of the oxidizer tube, a wellconditioned 800 slpm coflow of air or $\mathrm{N}_{2}$ was supplied in an $18.7 \mathrm{~cm}$ circular duct, giving an exit velocity of $0.49 \mathrm{~m} / \mathrm{s}$, to shield the flame from room disturbances and to provide a well-defined boundary condition for computational modeling [19]. 


\subsection{Flow conditions}

The flow parameters for the investigated flames are shown in Table 1. High-purity methane (99.97\%) and oxygen (99.98\%) were used, together with compressed, dry air. All flow rates were controlled via mass flow controllers that had been calibrated with laminar flow elements. The fuel and oxidizer flow rates were held constant for one series of flames, to maintain an identical (cold-flow) turbulent mixing field, while the concentration of oxygen in the oxidizer was varied. With a constant oxidizer flow rate, this meant that the stoichiometry of supplied gases varied with the concentration of oxygen in the oxidizer. With a surrounding shield flow of air, sufficient oxygen was entrained through mixing with the surrounding air to give overventilated flames, even for cases where the supplied gases were underventilated (i.e. fuel-rich).

To investigate the influence of the turbulent mixing intensity on soot formation and flame radiation, a second series of flames was investigated using pure oxygen in which the oxygen flow rate was varied by a factor of two (affecting both the turbulence intensity of the injected oxygen and its shear with the fuel stream and the low-velocity shield flow). Of course, the overall stoichiometry of the supplied gases necessarily varied in this series of flames, as well. To characterize the influence of mixing with the surrounding low-velocity shield gas, the highest flow condition was investigated for both a surrounding air flow and for a surrounding $\mathrm{N}_{2}$ flow. For all investigated flames the methane fuel flow rate was held constant, at a flow corresponding to a heat release rate of $12.1 \mathrm{~kW}$, and the flame was attached to the burner lip. Large industrial flames are generally lifted, but the large fuel nozzle size and fuel flow rates of industrial flames facilitate soot formation in a manner that cannot be duplicated in a lifted flame suitable for laboratory study. 


\subsection{Thermal radiation measurements}

Thermal radiation measurements were performed with a thin-film thermopile with a $\mathrm{CaF}_{2}$ window. The use of the $\mathrm{CaF}_{2}$ window material makes the radiometer equally sensitive to radiant emission from $0.13-$ $11 \mu \mathrm{m}$, encompassing nearly all of the energy-containing radiation from the flame. The thermopile is 1.0 $\mathrm{mm}$ in diameter and has a characteristic response time of $32 \mathrm{~ms}$. A black-anodized, $100 \mathrm{~mm}$ long steel tube with an ID of $3 \mathrm{~mm}$ was attached to the detector housing, restricting incident radiation to a solid

angle $(\Omega)$ of $1.61 \times 10^{-3} \mathrm{sr}$. The detector sensor was positioned $250 \mathrm{~mm}$ away from the burner centerline, so it measured radiation originating from a cone with a base of $9 \mathrm{~mm}$ at the flame centerline. During experiments, the burner was traversed axially and radially to measure radiation along different paths throughout the flames. The radiometer signal was recorded using LABVIEW in 10 second duration time records captured at 1000 samples/s. Each data record was then processed to give a mean, time-averaged signal. The radiation intensity was calibrated against a high-temperature blackbody source.

\subsection{Soot concentration measurements}

Laser-induced incandescence (LII) measurements were performed using a Nd:YAG laser operating at a $10 \mathrm{~Hz}$ repetition rate with a pulse duration of approximately $9 \mathrm{~ns}$. The laser output was attenuated to 152 $\mathrm{mJ} /$ pulse using a $1 / 2$-wave plate and glan-laser polarizer. A power meter was used to assure constant laser pulse energy before and after each series of measurements. The $1064 \mathrm{~nm}$ beam was formed into a vertical sheet using a $1000 \mathrm{~mm}$ focal length bi-convex spherical lens in combination with a $-76 \mathrm{~mm}$ focal length plano-concave cylindrical lens. The sheet height was clipped at $70 \mathrm{~mm}$ and the sheet thickness at the focus was $\sim 70 \mu \mathrm{m}$. The laser fluence was verified to be in the nominal 'plateau' region for making LII measurements with low sensitivity to variations in laser fluence. The laser sheet was positioned on the centerline of the flame and vertical traversing of the burner was used to move the measurement height. LII signals were detected using a Princeton Instruments PI-MAX fast-gating 
intensified CCD camera with a HQf GEN III intensifier and a CCD consisting of 512x512 pixels. The intensifier gate width was set to $120 \mathrm{~ns}$ with the center of the laser pulse arriving $16 \mathrm{~ns}$ after the onset of gate opening. A $600 \mathrm{~nm}$ low-pass filter was attached to the camera lens to minimize background contributions from natural flame luminosity.

To characterize the variation in soot concentrations and to form well-converged averages in these turbulent flames, 2000 planar LII images were collected at each measurement location, together with 500 images of background signal with the laser turned off. Examination of the single-shot images confirmed that the signal intensities were low enough that nonlinear camera response effects associated with high signal counts were negligible [21]. Figure 2 shows two sample images of instantaneous LII signals. The 2000 signal images were averaged at each location to form a mean signal image, from which the corresponding mean background image was subtracted. Calibration of the processed LII images for soot volume fraction was performed by comparing the LII field measured for a laminar $\mathrm{CH}_{4}$ flame established on the same burner against $532 \mathrm{~nm} \mathrm{cw}$ laser extinction measurements in the same flame that were tomographically inverted using the 3-pt Abel technique [22]. A dimensionless absorption coefficient, $K_{a}$, of 6.7 was assumed, as previously measured for non-premixed $\mathrm{CH}_{4}$ flame soot [23]. $K_{a}$ is defined through the Beer-Lambert law for line-of-sight absorption shown in Eqn. 1:

$$
I / I_{0}=\exp ^{-\int \frac{K a}{\lambda} f_{v} d x}
$$

where $f_{v}$ is the soot volume fraction and $\lambda$ is the wavelength of light. Based on the level of scatter for $K_{a}$ in ref. 23 , the uncertainty in this parameter is estimated to be $+/-10 \%$.

\subsection{Two-color pyrometry imaging}

Temperature measurements were performed in soot-containing flame regions using calibrated two-color imaging pyrometry. This was accomplished by splitting the naturally emitted light with a large optical 
beamsplitter and using two ICCD cameras, at right angles to one another, to image the soot thermal emission at wavelengths free from significant gas-band radiation. An optical target pattern was used to align and focus the two imaging systems to the central plane of the flame. Bandpass filters with center wavelengths of $550 \mathrm{~nm}$ and $675 \mathrm{~nm}$ and full-width half maximum (FWHM) bandwidths of $20 \mathrm{~nm}$ were used in front of the two cameras. Calibration of the two-color measurement was performed by replacing the flame with a high-temperature blackbody source. Extrapolation of the temperature response curve derived from the blackbody to very high temperatures was validated with imaging measurements of a calibrated tungsten lamp source with an apparent temperature of $2919 \mathrm{~K}$. With an intensifier gate width of $25 \mathrm{~ms}, 400$ image pairs were captured at each measurement location in the flame before averaging to form mean images. The measured green/red $(550 / 675 \mathrm{~nm})$ image ratios were first corrected for the nominal $1 / \lambda$ spectral dependence of soot particle emissivity in the visible region [24] before calculating the soot temperature from the calibrated image ratio. Mean soot temperature would be more precisely determined by averaging the instantaneous measurements of temperature, but the low signal-to-noise of the instantaneous images makes this approach exceedingly noisy. There is uncertainty regarding the precise spectral variation of flame soot emissivity, in general $[25,26]$, and one would naturally expect there to be variations depending on the level of maturity of the soot [23]. However, over the limited spectral range used for the two-color measurements here, the $1 / \lambda$ approximation should be reasonably accurate. To place a reasonable bound on the uncertainty in soot temperature based on this assumption, we have also processed the pyrometry data utilizing a relatively severe assumed spectral variation in soot emissivity of $1 / \lambda^{1.39}$ as suggested by Hottel and Broughton [27]. Using this assumption, the deduced soot temperatures are 60-90 K lower than reported here. 


\section{Results}

Figure 3 shows photographs of the investigated flames. The visible flame height of the tallest of these flames is approximately $600 \mathrm{~mm}$. In the Constant Mixing series of flames, the greatest flame height and strongest flame luminosity is evident for the $38 \% \mathrm{O}_{2}$ and $50 \% \mathrm{O}_{2}$ flames. The higher oxygen flow rates associated with the Variable Mixing flame series clearly reduce the flame height and the flame luminosity, while enhancing the blue chemiluminescence at the base of the flame (associated with $\mathrm{CH}^{*}$ ). Switching from air to $\mathrm{N}_{2}$ in the surrounding co-flow increases luminous flame height, suggesting that turbulent mixing of the burner oxygen stream with the surrounding bath gas is significant, at least for this 80 slpm flow case.

\subsection{Thermal radiation}

Figure 4 shows the measured centerline radiation intensities as a function of flame height for the two different series of flames that were investigated. The Constant Mixing series shows a consistently increasing radiation emission as the oxygen content of the oxidizer increases. In general, one would expect the radiant emission to increase with increasing oxygen concentration due to higher flame temperatures. Also, in this case the increase in oxygen concentration is also associated with an increase in the total amount of supplied oxygen, meaning that a greater portion of the flame brush is dominated by the composition of the supplied oxidizer, rather than the entrained air. Despite this consistent trend, note that combustion of methane in $75 \% \mathrm{O}_{2}$ produces radiant emission that is only $7 \%$ lower relative to combustion in pure oxygen (based on integrated centerline intensity) and the $50 \% \mathrm{O}_{2}$ radiation is only $14 \%$ lower. Also, note that the radiant flame heights (as indicated by the fall-off of the radiation profiles at a height of approximately $50 \mathrm{~cm}$ ) are essentially identical for these flames. The luminous flame heights apparent in Fig. 3 show a decreasing trend with increasing oxygen purity because less soot is formed and it burns out faster, as will be shown later. 
Consistent with the flame photographs shown in Fig. 3, the right side of Fig. 4 shows that the flow rate of the oxygen has a marked effect on the flame height and peak radiation intensity, with higher velocities (more intense mixing) associated with shorter and less radiant flames. The reduced radiation for the 80 slpm case with $\mathrm{N}_{2}$ surroundings presumably reflects lower flame temperatures due to rapid radial mixing of the supplied oxygen with the surrounding $\mathrm{N}_{2}$. Indeed the darker flame luminosity evident in Fig. 3 for this flame supports this interpretation. The integrated radiant intensity decreases by $19 \%$ for the 60 slpm flame and by $39 \%$ for the 80 slpm flame. The 80 slpm flame with a $\mathrm{N}_{2}$ shield flow has a $25 \%$ lower radiant intensity than the same flame with the air shield flow.

\subsection{Soot concentrations}

The mean soot volume fraction distributions in the most and least sooty flames are shown in Fig. 5. All of the mean soot images have maxima along the flame centerline and generally exhibit an ellipsoidal region with significant soot concentrations. Centerline profiles of soot volume fraction for all of the investigated flames are shown in Fig. 6. The soot concentrations in these flames are very low, never exceeding $0.06 \mathrm{ppm}$, on average. In fact, in the $80 \mathrm{slpm}$ flame with an air shield flow the mean soot concentration does not exceed $0.006 \mathrm{ppm}$. Figure 6 shows that there is a local maximum in the amount of soot formed at about $50 \% \mathrm{O}_{2}$. Soot formation decreases rapidly as one approaches $100 \% \mathrm{O}_{2}$ in the oxidizer. The right side of Fig. 6 shows that soot formation decreases rapidly as the mixing rate in the flame increases and the flame shortens. However, replacement of the shield air with $\mathrm{N}_{2}$ results in a much longer region of soot formation in the flame. 


\subsection{Soot temperatures}

Soot temperatures derived from the mean green/red signals are shown in Fig. 7. Signal cutoff points were established for the different flames on the basis of the strength of the emission signals relative to the strength of minor chemiluminescent signals that were apparent at the base of the flames and which tailed off with increasing height until thermal emission signals from soot rapidly rose and became dominant. All of the flames show an initial decrease in soot temperature with increasing height, before leveling off and generally rising modestly towards the tip of the flames, consistent with expectations during soot oxidation. The exception to this trend is the flame with a $\mathrm{N}_{2}$ shield gas, which shows a continuously decreasing soot temperature with increasing height. This is illuminating, as it suggests that the initial trend of decreasing soot temperature in all of the flames reflects the impact of the effective oxygen content of the oxidizing gas decreasing with height in the flame, because of turbulent mixing of the oxidizer flow with the surrounding shield gas. For the case with a $\mathrm{N}_{2}$ shield gas, the effective oxygen concentration continuously decreases with height, resulting in lower local flame temperatures and lower soot temperatures. For the other flames, with an air shield gas flow, the supplied oxidizer mixes with the air, resulting in a lower effective oxygen concentration with increasing height initially, until the local oxidizer has an oxygen content similar to that of air. Another factor to consider in the soot temperature

trends is the variation in the stoichiometry of the supplied gas streams. The flames with a $50 \% \mathrm{O}_{2}$ and $38 \% \mathrm{O}_{2}$ oxidizer were significantly deficient in supplied oxygen, so the supplied oxygen would tend to be consumed low in the flame, thereby relying on entrained air from the shield flow to consume the fuel towards the top of the flame. Indeed these two flames showed a consistent soot temperature of just over 
$2000 \mathrm{~K}$ for heights above $30 \mathrm{~cm}$, as might be expected for soot in methane/air flames (with an adiabatic flame temperature of $2225 \mathrm{~K}$ [20]). In general, the expected trends of greater soot temperatures for greater oxygen purity and greater flow rate of pure oxygen (thereby reducing the impact of entrained air on the flame temperature) are evident.

\section{Discussion}

The soot temperature results show that the effect of entrainment of the surrounding shield gas into the upper portions of the flames, where soot tends to form when burning methane, must be considered when interpreting the impact of soot formation and radiation on the total radiation from the investigated flames. This is certainly also true for the long, thin turbulent flames used in industrial heating furnaces [28], though in that case the shield gas is generally composed of hot flame products (with very low residual $\mathrm{O}_{2}$ ). It is evident from the trends in total thermal radiation and soot formation for the Constant Mixing series of flames that an increase in soot formation as the oxygen purity decreases tempers the reduction in flame radiation that would otherwise occur. Indeed the measured reduction in flame radiation with reduced $\mathrm{O}_{2}$ content seen in the flames investigated here is much weaker than the reduction seen previously in a rapid mixing burner that did not produce soot [17]. That said, the soot concentrations are still very low in these turbulent methane flames, such that most of the thermal radiation emanates from hot $\mathrm{CO}_{2}$ and $\mathrm{H}_{2} \mathrm{O}$ in the flame products.

In the Variable Mixing series of flames, the trends in thermal radiation and soot formation are aligned, with increasing mixing rates dramatically reducing both soot formation and overall thermal radiation as the flame is shortened. In this case, the reduction of soot formation with increasing mixing rates combines with the more rapid mixing of oxygen with shield gas and of flame products with shield gas to reduce the overall thermal radiation from the flames. Note that this reduction in radiation occurs despite an increase in the temperature of the soot. From the perspective of burner design, clearly it is 
desirable to minimize the mixing rates between the fuel and oxygen and between the oxygen and the surrounding gas in order to produce long, luminous flames.

\section{Conclusions}

Measurements of soot volume fractions, soot temperatures, and thermal radiation in two different series of turbulent, non-premixed oxygen-enriched methane jet flames have demonstrated the pronounced effect of turbulent mixing intensity and moderate impact of oxygen purity on soot formation and thermal radiation. For flames with lower mixing intensities, the results show only a weak dependence of thermal radiation on the oxygen purity (i.e. the radiation increases by $14 \%$ as the $\mathrm{O}_{2}$ purity increases from $50 \%$ to $100 \%$ ) and a tendency to enhance soot formation as the oxygen purity decreases. The soot temperatures decrease from approximately $2400 \mathrm{~K}$ to $2050 \mathrm{~K}$ with decreasing oxygen purity over this range of $\mathrm{O}_{2}$ purities. For pure oxyfuel flames with variable oxidizer flow rates, the soot formation and flame radiation both decrease rapidly as the turbulent mixing rate increases, concurrent with a small increase in soot temperature. Finally, the results from a highly turbulent flame with a $\mathrm{N}_{2}$ shield gas show that mixing of the turbulent burner gases with the surrounding gas is rapid and impacts the local flame temperature and thereby the soot temperature as the flame extends downstream.

\section{Acknowledgments}

Support for this research was provided by Sandia National Laboratories' Laboratory Directed Research and Development program. Sandia National Laboratories is a multiprogram laboratory managed and operated by Sandia Corporation, a wholly owned subsidiary of Lockheed Martin Corporation, for U.S. DOE’s National Nuclear Security Administration under contract DE-AC04-94AL85000.

\section{References}


[1] C.E. Baukal, Jr., Oxygen-Enhanced Combustion, $2^{\text {nd }}$ Ed., Taylor \& Francis Group, Boca Raton, FL, 2013.

[2] W.J. Horan, A.G. Slavejkov, L.L. Chang, Ceram. Eng. Sci. Proc. 17 (1996) 141-151.

[3] L.M. Farrell, T.T. Pavlack, L. Rich, Iron Steel Eng. 72 (1995) 35-42.

[4] S. Grisham, Am. Glass Rev. 117 (1997) 12.

[5] J.J. Schep, Ceram. Eng. Sci. Proc. 30 (2009) 3-11.

[6] A.R. Smith, J. Klosek, Fuel Process. Technol. 70 (2001) 115-134.

[7] W.F. Castle, Int. J. Refrig. 25 (2002) 158-172.

[8] D.M. Ruthven, S. Farooq, Gas Sep. Purif. 4 (1990) 141-148.

[9] J. Sunarso, S. Baumann, J.M. Serra, W.A. Meulenberg, S. Liu, Y.S. Lin, J.C. Diniz da Costa, J. Membrane Sci. 320 (2008) 13-41.

[10] S.M. Hashim, A.R. Mohamed, S. Bhatia, Adv. Coll. Inter. Sci. 160 (2010) 88-100.

[11] M. Eddaoudi, H. Li, O.M. Yaghi, J. Am. Chem. Soc. 122 (2000) 1391-1397.

[12] D.F. Sava Gallis, M. Parkes, J.A. Greathouse, X. Zhang, T.M. Nenoff, Chem. Mater. 27 (2015) 2018-2025.

[13] M. Parkes, D.F. Sava Gallis, J.A. Greathouse, T.M. Nenoff, J. Phys Chem C 119 (2015) 6556-6567.

[14] L. Wang, M.F. Modest, D.C. Haworth, S.R. Turns, Combust. Theor. Model. 9 (2005) 479-498.

[15] A.A.B. Santos, A.A. Torres, P.A. de Paula Pereira, Energy 36 (2011) 1527-1534.

[16] L. Wu, N. Kobayashi, Z. Li, H. Huang, Can. J. Chem. Eng. 93 (2015) 1567-1576.

[17] C.E. Baukal, B. Gebhart, Int. J. Heat Mass Trans. 40 (1997) 2539-2547.

[18] L. Wang, N.E. Endrud, S.R. Turns, M.D. D’Agostini, A.G. Slavejkov, Combust. Sci. Technol. 174 (2002) 45-72.

[19] R.S. Barlow, Proc. Combust. Inst. 31 (2007) 49-75.

[20] NASA (2006) http://www.grc.nasa.gov/WWW/CEAWeb/ 
[21] T.C. Williams, C.R. Shaddix, Rev. Sci. Instr. 78 (2007) 123702.

[22] C.J. Dasch, Appl. Optics 31 (1992) 1146-1152.

[23] T.C. Williams, C.R. Shaddix, K.A. Jensen, J.M. Suo-Antilla, Int. J. Heat Mass Trans. 50 (2007) 1616-1630.

[24] S.S. Krishnan, K.-C. Lin, G.M. Faeth, J. Heat Trans. 122 (2000) 517-524.

[25] H.A. Michelsen, P.E. Schrader, F. Goulay, Carbon 48 (2010) 2175-2191.

[26] F. Goulay, P.E. Schrader, H.A. Michelsen, Appl. Phys. B 100 (2010) 655-663.

[27] H. Hottel, F. Broughton, Ind. Eng. Chem. 4 (1932) 166-175.

[28] A.G. Slavejkov, T.M. Gosling, R.E. Knorr, Jr., US Patent No. 5,575,637. 


\section{FIGURE CAPTIONS}

Figure 1. Schematic and photograph of the turbulent co-annular flow burner with shield gas flow.

Figure 2. Typical images of instantaneous LII signal intensity (i.e. relative soot volume fraction).

Figure 3. Digital SLR camera photographs of oxygen-enriched (left-side) and oxyfuel flames (right

side) for the conditions given in Table 1. All photographs were taken with the same camera exposure.

Note that the flames (and photographs) labeled " $100 \% \mathrm{O}_{2}$ " and " $40 \mathrm{slpm"}$ " are identical, as this flame is part of both flame series.

Figure 4. Centerline profiles of mean thermal radiation emitted from the two series of flames, with the Constant Mixing series to the left and the Variable Mixing series to the right.

Figure 5. Calibrated false-color mean LII images of the mean soot volume fraction in the $50 \% \mathrm{O}_{2}$ flame (40 slpm), left, and the $100 \% \mathrm{O}_{2}, 80$ slpm flame, right.

Figure 6. Centerline profiles of mean soot volume fraction from the two series of flames, with the Constant Mixing series to the left and the Variable Mixing series to the right.

Figure 7. Centerline profiles of mean soot temperature from the two series of flames, with the Constant Mixing series to the left and the Variable Mixing series to the right. 

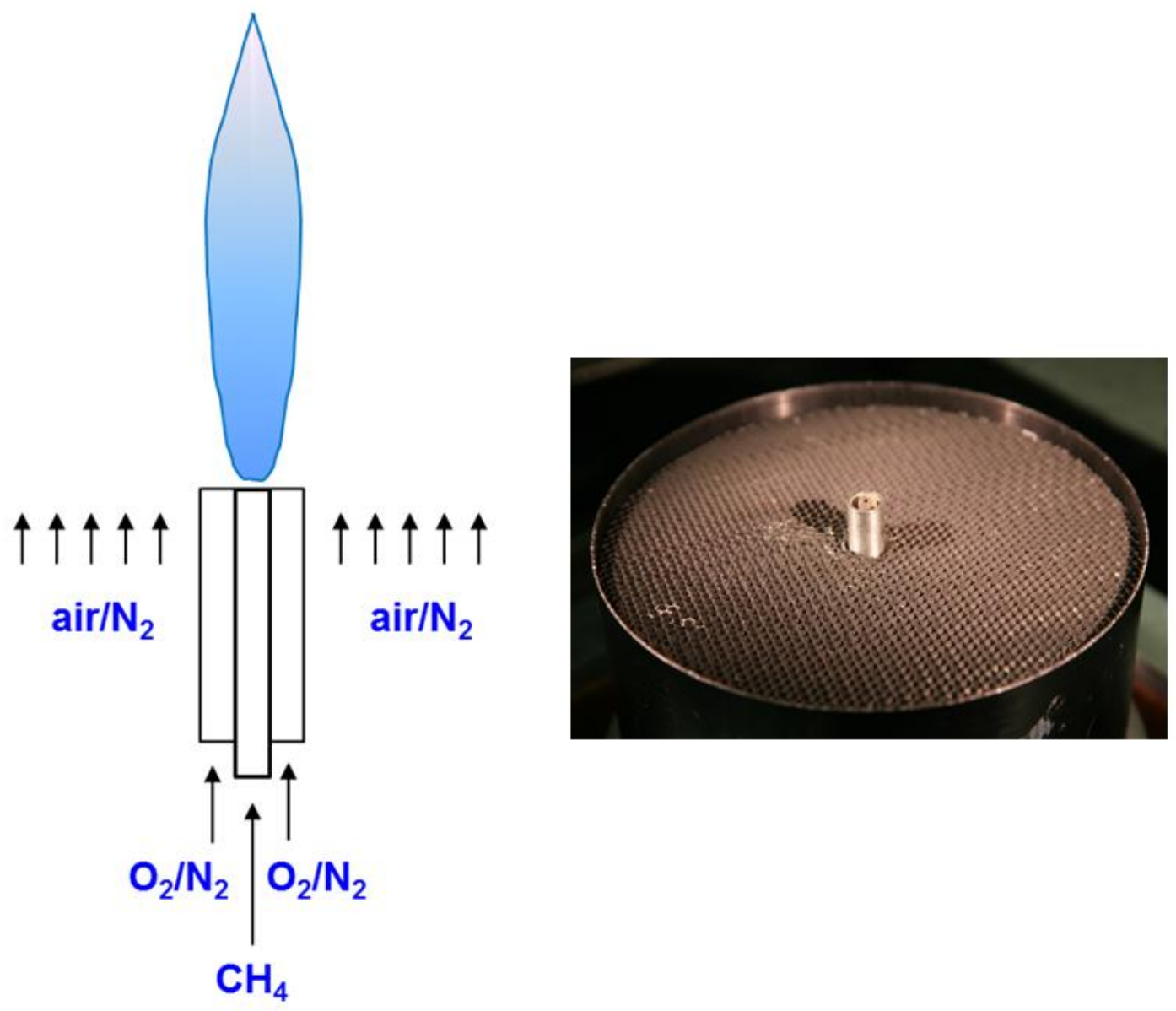

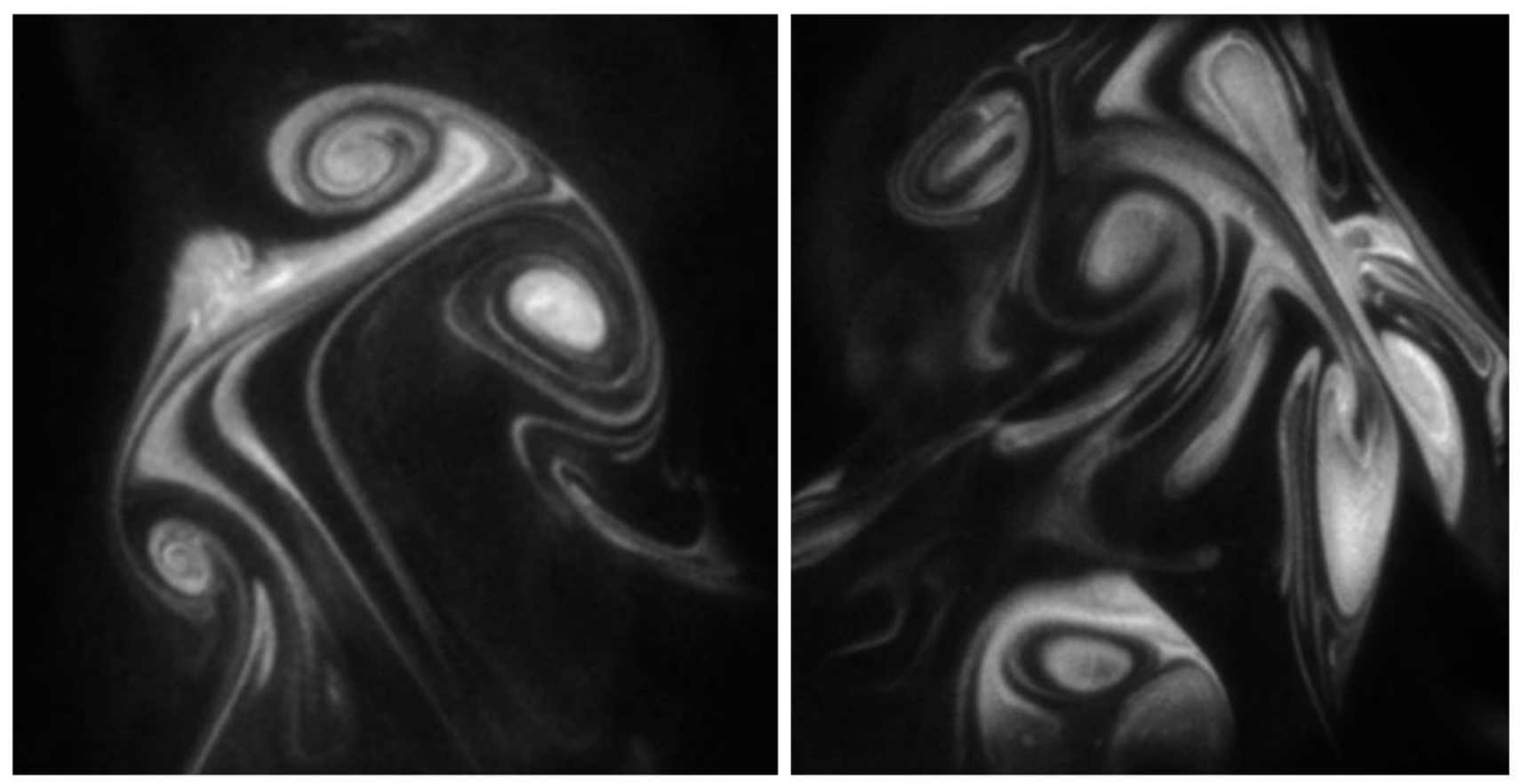


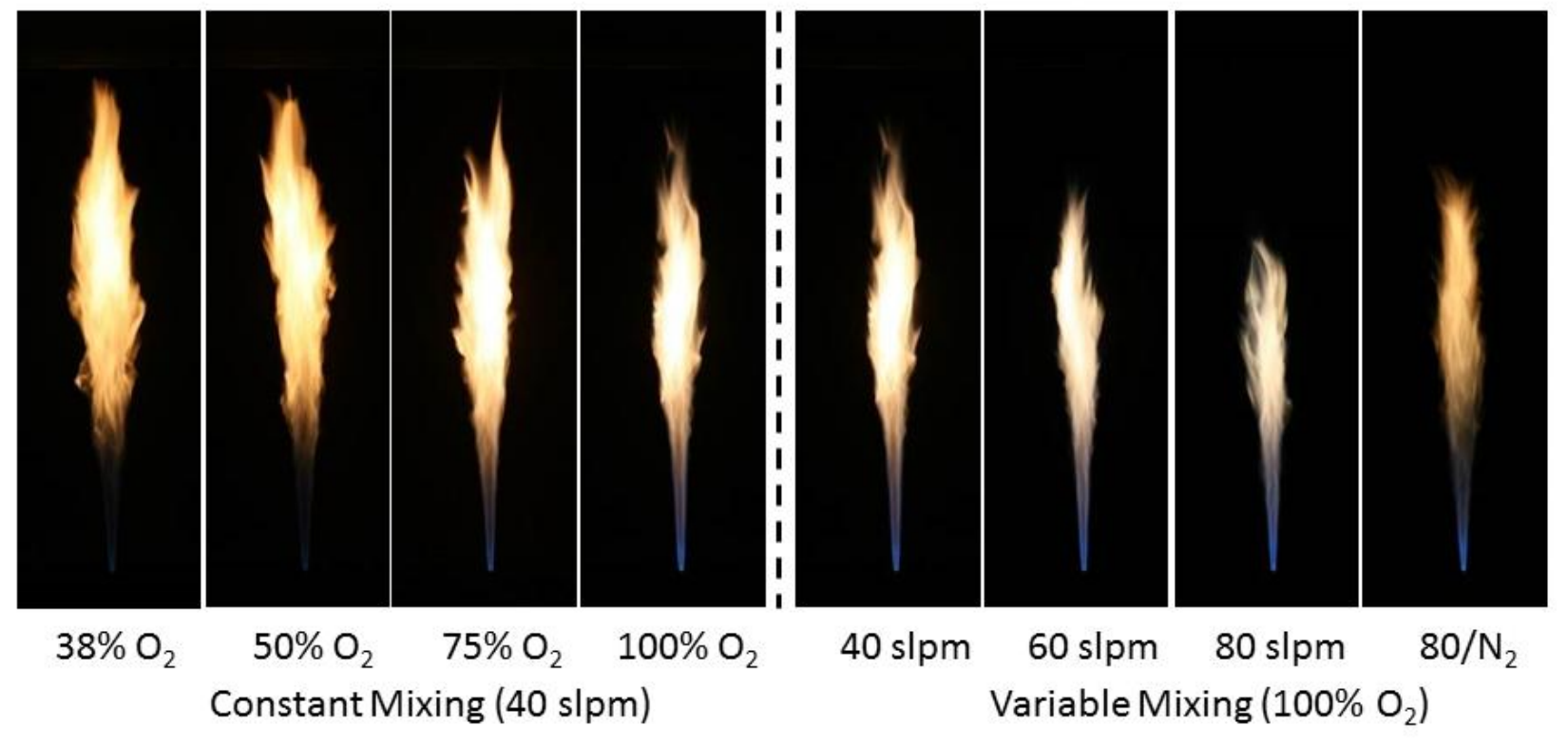




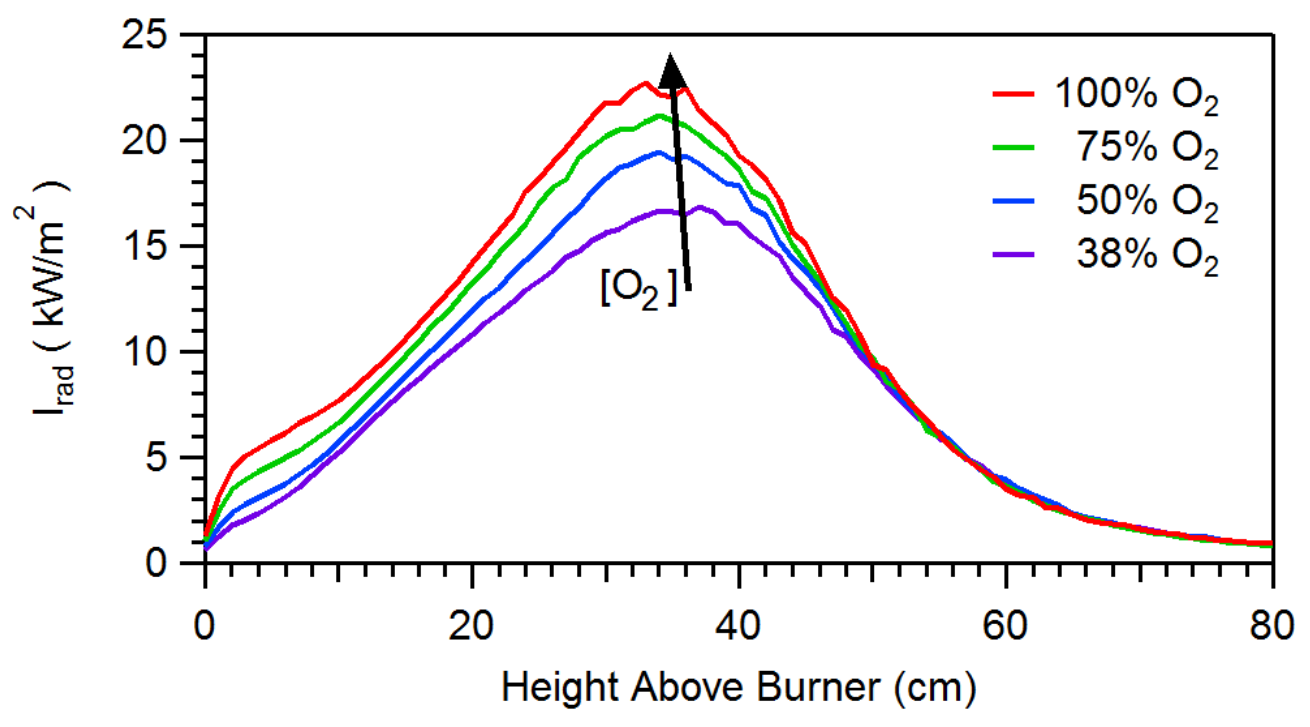




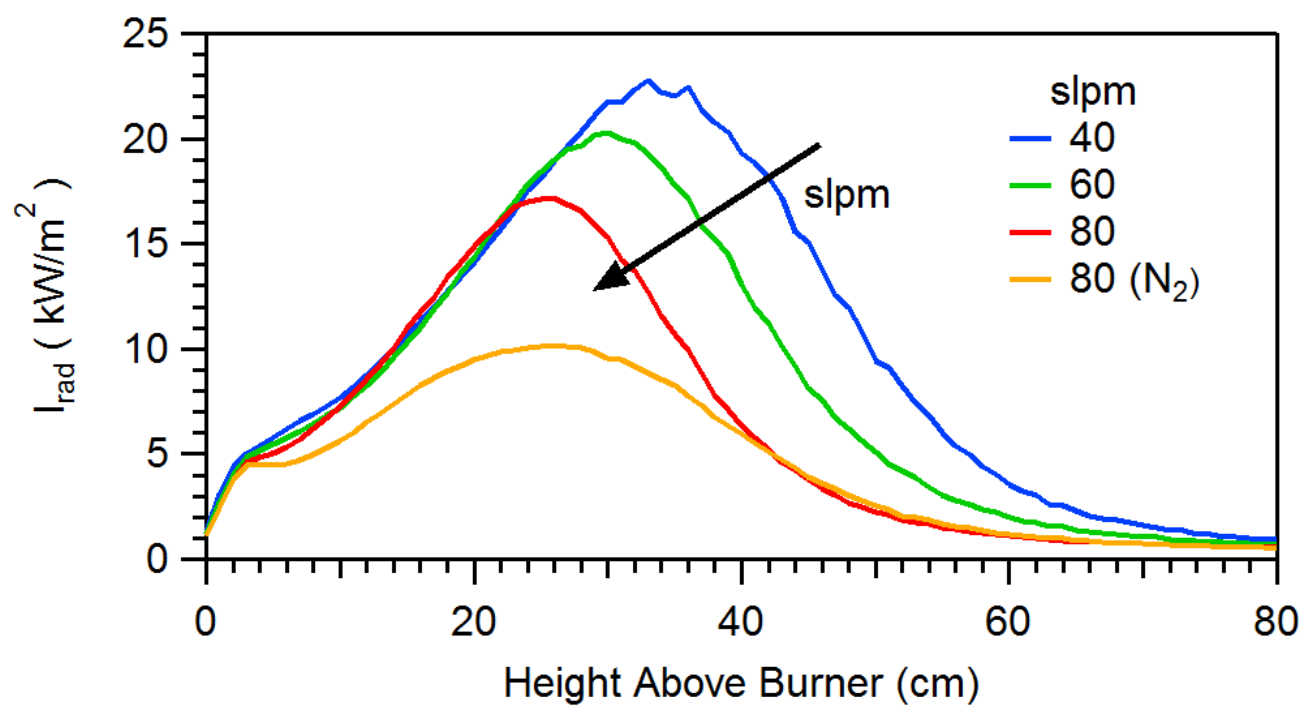




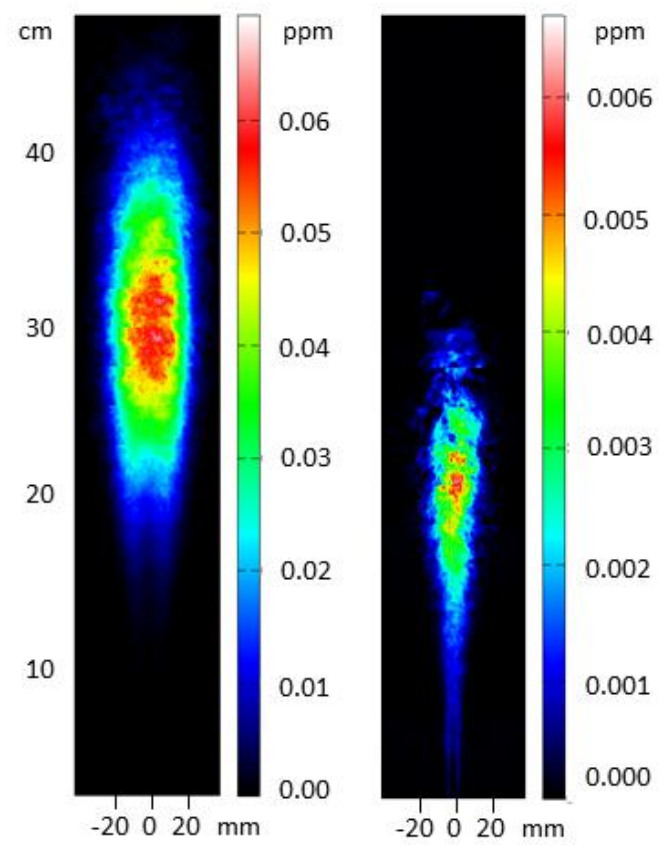




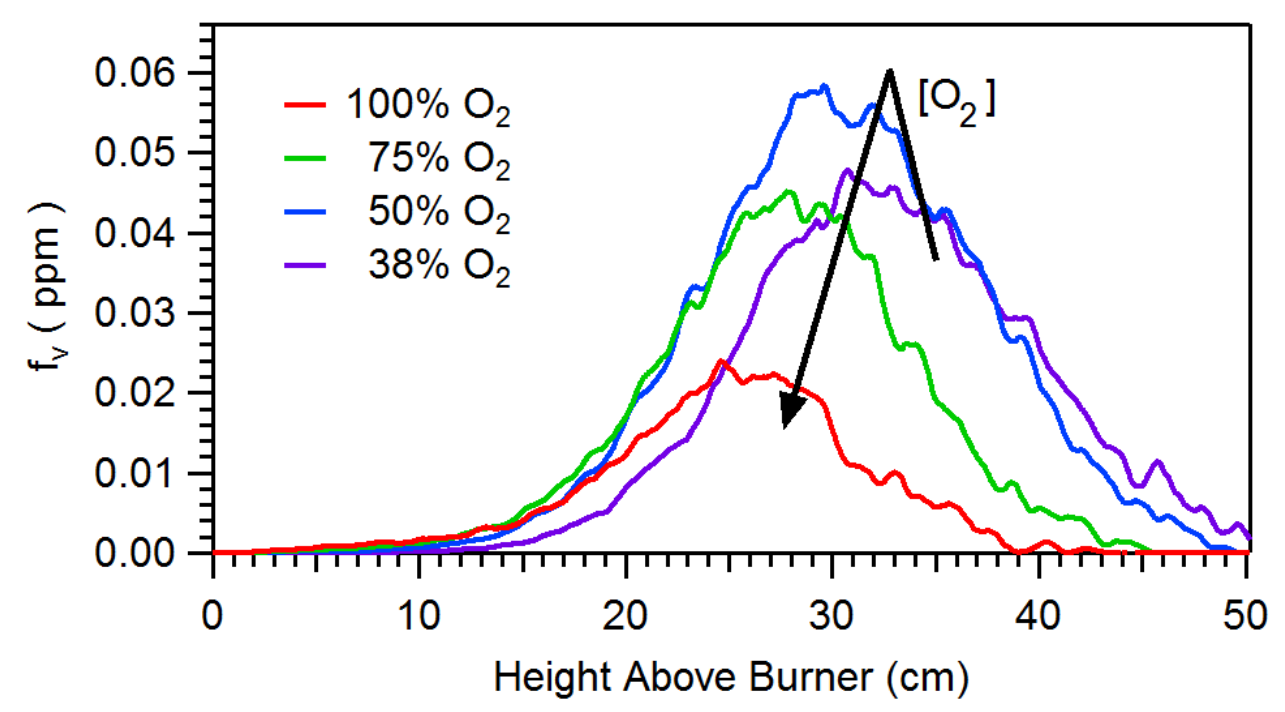




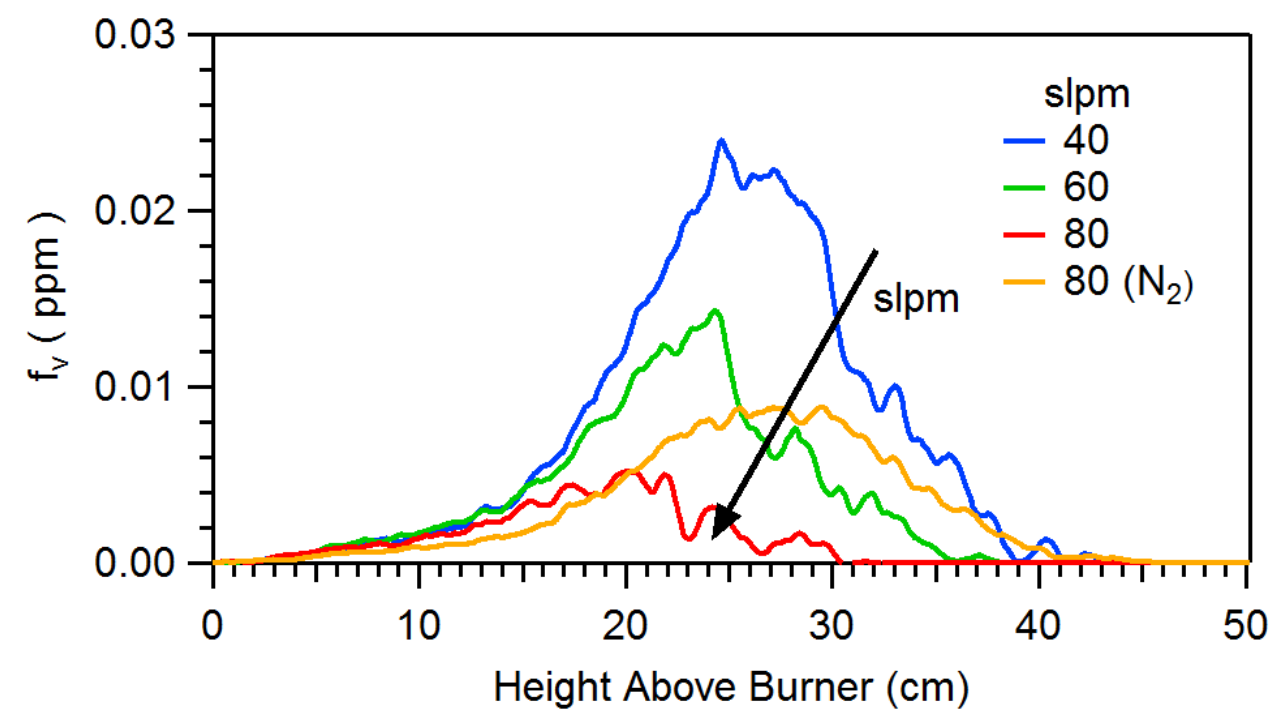




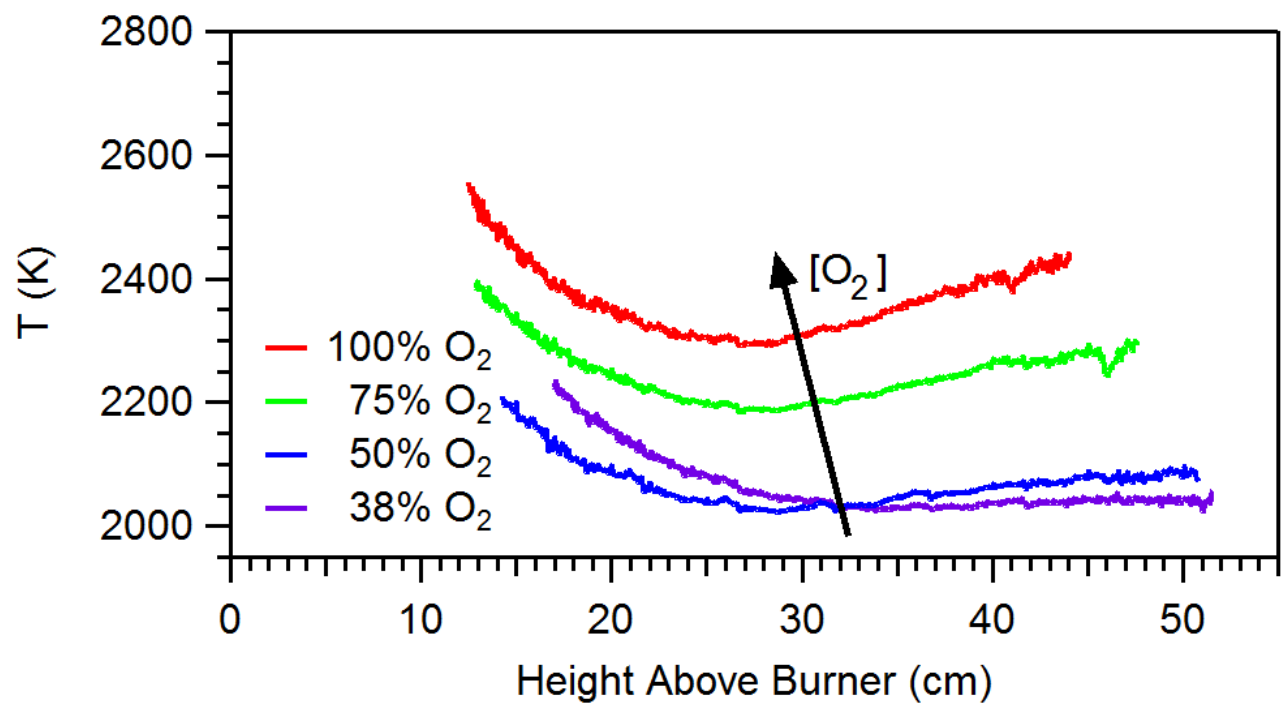




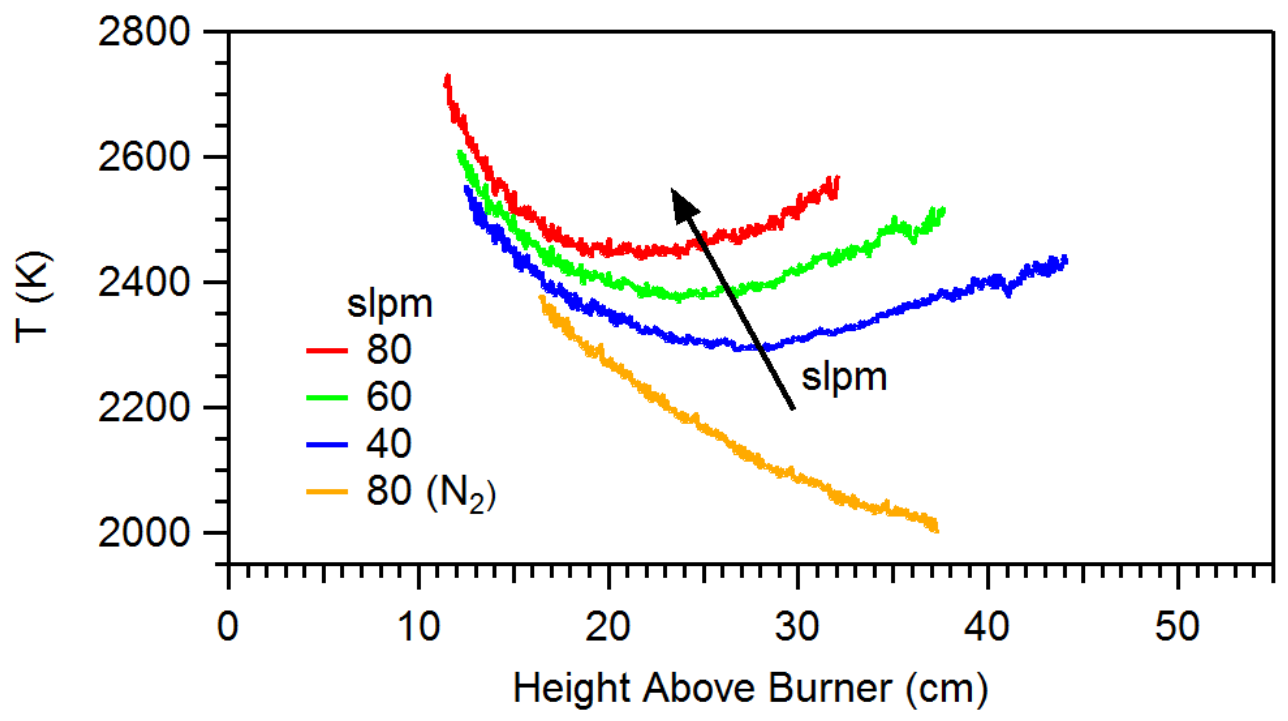


Table 1: Flow Parameters of Investigated Flames

\begin{tabular}{|c|c|c|c|c|c|c|c|c|c|c|}
\hline \multirow{2}{*}{$\begin{array}{l}\text { Flame } \\
\text { Series }\end{array}$} & \multicolumn{3}{|c|}{$\mathrm{CH}_{4}$} & \multicolumn{4}{|c|}{ Oxidizer } & \multirow{2}{*}{$\phi^{\dagger}$} & \multirow{2}{*}{$\mathrm{T}_{\mathrm{ad}}^{\ddagger}(\mathrm{K})$} & \multirow{2}{*}{$\begin{array}{l}\text { Shield } \\
\text { gas flow }\end{array}$} \\
\hline & slpm ${ }^{*}$ & $\mathrm{~m} / \mathrm{s}$ & $\operatorname{Re}$ & $\% \mathrm{O}_{2}{ }^{\ddagger}$ & slpm & $\mathrm{m} / \mathrm{s}$ & $\operatorname{Re}$ & & & \\
\hline \multirow{4}{*}{$\begin{array}{c}\text { Constant } \\
\text { Mixing }\end{array}$} & 20.0 & 38.0 & 7680 & 38 & 40.0 & 10.4 & 3660 & 2.67 & 1467 & air \\
\hline & & & & 50 & & & & 2.0 & 2240 & \\
\hline & & & & 75 & & & & 1.33 & 2949 & \\
\hline & $\downarrow$ & $\downarrow$ & $\downarrow$ & 100 & $\downarrow$ & $\downarrow$ & $\downarrow$ & 1.0 & 3054 & $\downarrow$ \\
\hline \multirow{4}{*}{$\begin{array}{l}\text { Variable } \\
\text { Mixing }\end{array}$} & 20.0 & 38.0 & 7680 & 100 & 40.0 & 10.4 & 3660 & 1.0 & 3054 & air \\
\hline & & & & & 60.0 & 15.6 & 5490 & 0.67 & 2971 & \\
\hline & & & & & 80.0 & 20.8 & 7320 & 0.5 & 2861 & $\downarrow$ \\
\hline & $\downarrow$ & $\downarrow$ & $\downarrow$ & $\downarrow$ & 80.0 & 20.8 & 7320 & 0.5 & 2861 & $\mathrm{~N}_{2}$ \\
\hline
\end{tabular}

* standard conditions defined to be $298 \mathrm{~K}$ and 1 atm. pressure

$¥$ balance gas of $\mathrm{N}_{2}$

${ }^{\dagger}$ stoichiometry of supplied gases

‡ adiabatic flame temperature of supplied gases (calculated using NASA cea code [20]) 